Front. Educ China 2010, 5(4): 465-472

DOI 10.1007/s11516-010-0111-1

Special Issue Editorial

\title{
Ruth HAYHOE
}

\section{A Narrative Background to the Study}

\author{
(C) Higher Education Press and Springer-Verlag 2010
}

It is both an honor and a pleasure for me to be co-editing this special issue of Frontiers of Education in China with Professor Yan Fengqiao of Peking University. We have worked together since launching this study of China's move to mass higher education in 2006, with ever increasing commitment and involvement from our Chinese partners, as will be evident in the introduction Professor Yan has written to follow this one. There he reflects on the difference between the perspectives of insiders and outsiders in observing and interpreting the dramatic changes taking place in universities over these years, and the tensions that have emerged in the process. He calls particular attention to deeply rooted institutional patterns shaped by Chinese culture, which have influenced the change process. Given the succinct and highly analytic character of Professor Yan's introductory remarks, it seemed appropriate for me to adopt a more narrative approach. This is intended to give readers some background to the ideas that lay behind the project and the ways it has unfolded over a five-year period.

When we began to design this research in the summer and autumn of 2005 , China was in the seventh year of massive enrollment expansion for its higher education system, which had raised student numbers nationwide from 7.2 million in 1999 to 23 million in 2005 ( $\mathrm{Li} \& \mathrm{Lin}, 2008$, p. 271), while at the same time providing extraordinary support for a few leading universities to strive for world class standards and standing. As we reflected on this situation, it became clear that these changes had momentous importance both for Chinese society and for the global community. Firstly, Chinese universities would have much to bring to the world community, once they were able to be actors on a global stage, since they are rooted in a civilization that has made rich historical contributions to human development. What ideas and concepts might they draw from these indigenous cultural resources that could bring new insights to global educational circles? Secondly, as the world's largest nation in terms of population, how

Ruth HAYHOE $(\square)$

The Ontario Institute for Studies in Education, The University of Toronto, Toronto M5S1V6, Canada

E-mail: hayhoe@bellsouth.net 
would the opening up of higher education to a hugely expanded student body affect civil society development and democratization? This is obviously a question of concern both to China's citizens and to those of other nations who have more and more dealings with China in various geo-political arenas. Finally, the logistics of such a rapid move to mass higher education were startling. How did this move impact issues of equity of access and system diversification? Were there lessons that could be helpful to other countries?

These were the three broad questions which were foremost in our minds as we designed a research plan and decided on the specific research approaches and techniques we would use. In order to understand the broad policy perspective behind the move, we arranged interviews with both government officials and scholars of higher education at the national and regional levels during the autumn of 2006 (Zha \& Lin, in press). Then beginning in 2007 we selected twelve universities as case studies, in order to understand how the changes had been initiated and carried through at the institutional level, from the perspective of university leaders, faculty members and students, and how the results of these changes were viewed. Our intention was not to impose theories from the international literature to the interpretation and understanding of the roles and responsibilities of Chinese universities over this period of dramatic change, rather to observe and listen to the self understanding of those directly involved in the changes. The book that has come out of the study is thus titled Portraits of 21st Century Chinese Universities: In the Move to Mass Higher Education and we are delighted that it will be published by the Comparative Education Research Center, University of Hong Kong, together with Springer (Hayhoe, Li, Lin, \& Zha, in press).

Not long ago, I published another book entitled Portraits of Influential Chinese Educators (Hayhoe, 2006), which told the stories of eleven influential Chinese educators, and interpreted them in the context of Confucian educational values and ideas, broadly defined. Each of the educators was a unique individual, who had made remarkable contributions in both educational thought and action. They had grown up in different time periods and different regions of China, and had served within different institutions in all the major regions of China. Their lives and educational ideas were thus quite diverse, yet there were certain threads that bound them together, reflecting their shared educational heritage. This book aims to serve a similar purpose, presenting portraits of twelve contemporary universities, which have certain common features that may be interpreted by reference to their shared heritage in classical Chinese civilization, while also having diverse characteristics that reflect different histories and geographical locations, also different visions and strategies that have been adopted in the increasing autonomy they have enjoyed in recent years. 
The selection of the case universities was a delicate and demanding process. Given the importance of geography in China's development and the gaps that were emerging between the dynamic and economically vibrant eastern coastal region and the central and western regions, we wanted to choose institutions that could represent different geographic areas in a balanced way. A second consideration was the diversity of university types. Chinese higher education had been divided into a number of major sectoral types in the 1950s, including comprehensive universities, science and engineering universities and normal or teacher-education universities, as well as many narrowly specialized institutions serving specific sectors of the economy. While most of the specialized universities that had been administered by ministries such as agriculture, health, finance and machine-building have been merged and in some cases moved to the jurisdiction of provincial authorities, the main comprehensive, engineering and education-related institutions have retained their unique identities in the reform process. We thus chose three universities of each general type that were located in widely differing geographic regions. Finally, we decided it was important to include three of the newly burgeoning private universities which have developed since the late 1980s. While these institutions are far from the standing and status of major public universities, they are developing rapidly and could benefit from a tradition of excellence in private higher education before the 1949 revolution. Thus a few may have promise to become strong intellectual institutions in the longer term future.

Why did we choose national level universities of significant reputation, when it is clear that provincial and local level universities have carried the main burden of enrollment expansion at the undergraduate level? This was a carefully considered judgment that relates to our first question, about the ethos which Chinese universities are developing in the 21st century, and the cultural resources they are bringing into global educational circles. Clearly it is nationally prestigious universities that have the conditions to become global actors and to exercise influence beyond China's borders. By the same token, we selected three of the most outstanding private universities, institutions that are not typical of the wide range of private higher education.

Thus our slate of institutions included Peking University (PKU) in the national capital, Nanjing University (NJU) in the dynamic coastal province of Jiangsu, and Xiamen University (XMU) in the southeastern province of Fujian, looking out on the Taiwan straights. All three are leading comprehensive universities. For education-related universities, we selected East China Normal University (ECNU) in the city of Shanghai, Southwest University (SWU) in the major southwestern city of Chongqing, which has recently become an independent 
municipality under central government jurisdiction, and Yanbian University (YBU) in the Northeastern Korean minority region of Yanji, close to the border of North Korea. For science and technology institutions, we selected the University of Science and Technology of China (USTC) in the eastern province of Anhui, the Huazhong University of Science and Technology (HUST) in the central city of Wuhan, and the Northwest University of Agriculture and Forestry Science and Technology (NWAFU) in Yangling, a small city near Xi'an in Northwest China. Finally, the three private universities selected for the study are also found in diverse geographical regions, the Yellow River University of Science and Technology (HHUST) in Henan Province, the Xi'an International University (XAIU) in the northwestern city of Xi' an and the Blue Sky University (BSU) in the southeastern province of Jiangxi. Fig. 1 shows the geographic location of the twelve case institutions:

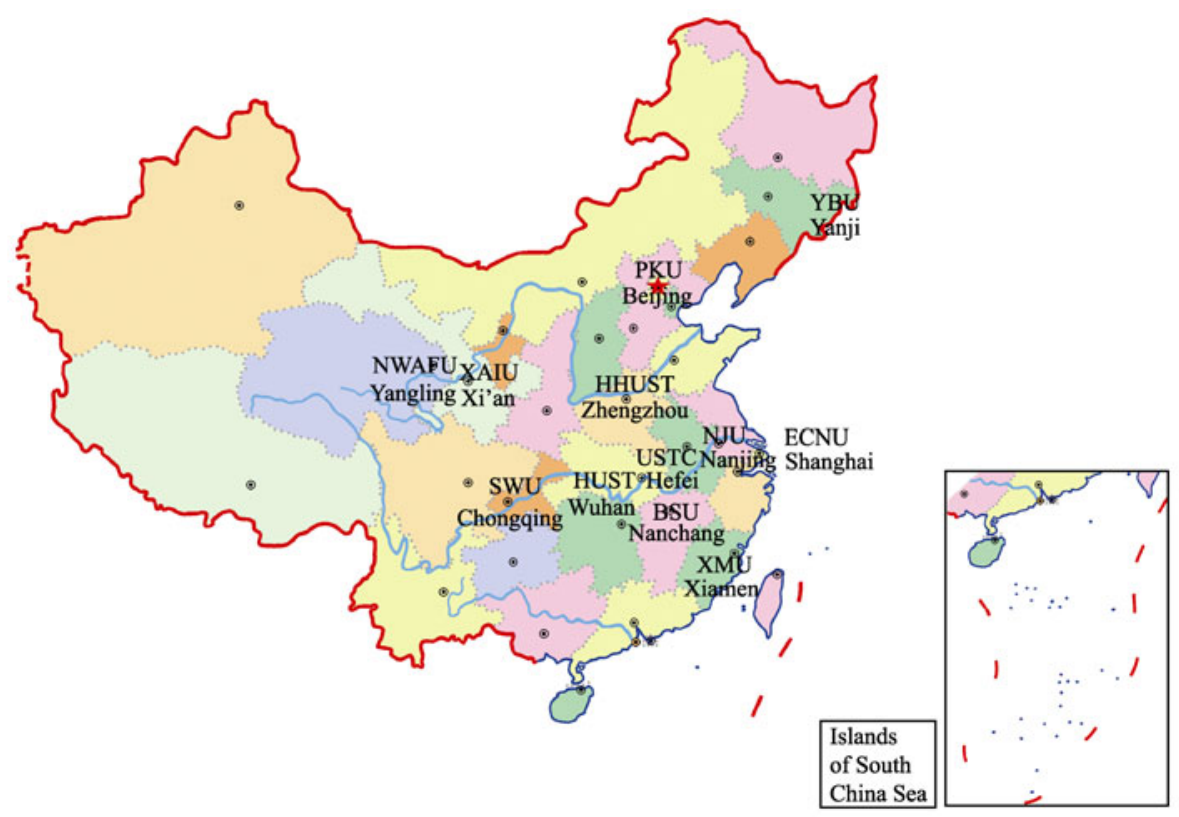

Fig. 1 The Geographic Location Map of Twelve Case Institutions

Our core research team included four scholars, Professor Jing Lin of the University of Maryland Professor Qiang Zha of York University in Toronto, Dr. Jun Li who served the project as a postdoctoral fellow and is now assistant professor at the Hong Kong Institute of Education and Ruth Hayhoe, the author of this introduction. In addition we invited one senior scholar in each of the case universities to collaborate with us. In carrying out the case study research, we 
divided into two teams of two, and visited six universities in the spring of 2007, and another six universities in the spring of 2008, working with our collaborating scholar in each institution. Over this period we also carried out a survey of three classes of third year students in the fields of humanities, social sciences and sciences and technology in each of the universities, in order to get a broad understanding of student perspectives on the move to mass higher education and their experiences of civil society participation (Li, 2009).

Our approach to the case studies was inspired by the work of Burton Clark, whose notion of the "entrepreneurial university" provided a compelling example of the development of a grounded theory that both explored and explained the emergence of entrepreneurial universities and their new roles (Clark, 1998). Our core question was quite a different one, of course, as we wanted to see if an emerging Chinese model of the university might be identified and whether it could be interpreted in relation to persisting elements in China's cultural and scholarly traditions. We also wanted to understand how the increasing autonomy of Chinese universities was being expressed in the diverse approaches to reform and strategic planning on individual campuses, and how far faculty members and students were participating in key decision-making processes.

The interviews which we held with university leaders on each campus, and the focus group meetings with faculty members and students, were facilitated by the collaborating scholar who joined our team in each institution. These scholars also assisted us in gaining access to important documents, such as mission statements, teaching assessment reports and research policies and outcomes. Furthermore they helped us in collecting a set of base data for each institution, which gave an empirical account of changes in undergraduate and graduate enrollment, faculty appointments and qualifications, curricular developments, as well as key financial data, over the period from 1990 to 2005. One of the most interesting aspects of our case study work was the identification of spaces or buildings on each campus by university leaders, faculty and students, separately, as symbols that they felt expressed the university's ethos. These were photographed and included for illustration in the portraits.

The work of writing the first drafts of the institutional portraits was done by one of the core research team members in each case. It was a demanding exercise to interpret the factual material and opinions gathered in ways that made sense of the dramatic changes that had taken place and their outcomes in relation to each university's history and contemporary role within China's higher education system. We wanted to make sure that our collaborating scholars from each of the campuses had the opportunity to give us feedback before these chapters were finalized, and thus we organized a workshop in May of 2009, when the first drafts of fourteen of the fifteen chapters in Portraits of 21st Century Chinese Universities were opened up for discussion. Ten of the twelve collaborating 
scholars were able to participate, as well as a number of other senior higher education scholars based in other Beijing universities. We also used this opportunity to garner viewpoints for Chapter Fifteen, the final chapter of the Portraits, which seeks to sketch out the emerging model of the Chinese university in the 21 st century. All were invited to give their comments and criticisms. We are particularly grateful to Peking University and Professor Yan Fengqiao for hosting this workshop in their newly opened Graduate School of Education Building on Peking University's beautiful campus. We would also like to acknowledge the support given to us by Professor Min Weifang, Peking University's Party Secretary and Chairman of Council, who took a strong interest in the project from its inception.

The discussions that took place at this workshop were so lively that we felt it was important to provide a more organized forum for our collaborating scholars to present their views on the transformations taking place in Chinese universities. As a result we invited four of them to prepare papers for a panel at the Annual Meeting of the Comparative and International Education Society in Chicago, in March of 2010, giving their analyses and reflections on the experiences of each of the four types of university in the study. That was the genesis of this special issue of Frontiers of Education in China with articles respectively on the transformation of comprehensive universities, education-related universities, science and technology universities and private universities. The lead author in each case is one of the collaborating scholars, while three of the four articles have been co-authored by core members of our original research team.

As Professor Yan points out in his introduction to this special issue, scholars working within China's mainland tend to have both a more realistic and a shorter-term perspective on the changes taking place in their universities, as well as being somewhat more critical than members of our core team. While we have tried to interpret the changes in relation to broad trends of history and culture, they are deeply concerned about the immediate tensions and problems emerging in the change process, as well as being conscious of their responsibility to provide constructive criticism that may move the reforms in a positive direction. It is also interesting to see the ways in which each of the collaborating scholars has made use of theories current in the international higher education and sociological literature to reflect on the Chinese experience, including critical realism, systems theory, multi-stream analysis, Brubacher's dual framework for university roles and Clark's triangle of state, market and academic actors.

This special issue may thus be read in a number of ways. It can be seen as a response from within to a set of portraits of contemporary Chinese universities developed by scholars who are an ocean removed from the realities and struggles of daily life on Chinese campuses. While the book has identified many positive 
aspirations in newly developed mission statements and strategic plans, and explored how these reflect valued aspects of China's scholarly civilization, the articles show that there are also constraining aspects of China's cultural heritage that are deeply embedded in educational and political institutions and may inhibit needed change. Thus there is a sense of struggle and a realization that tradition must be understood at a deep level and critically adapted to new circumstances if it is to be a source of energy for change. The book and the four articles are thus complementary in the different emphases they bring to their scrutiny of the change process.

The articles can also be read as a stand-alone analysis of different dimensions of China's higher education reform in four main types of university in an era when there has been an unprecedented increase in autonomy as well as tremendous challenges and demands. Each article also exemplifies the ways in which Chinese scholars in the field of higher education are linking concepts and frames of analysis from their own heritage with theories and paradigms being used in the international research literature.

This special issue is timely, given "The National Guidelines for Medium- and Long-Term Educational Reform and Development (2010-2020)," which have been recently released and which give a high priority to issues of equality, quality and diversity in higher education. It is precisely the balancing of these contesting priorities that makes the task of university leaders so challenging, as they strive for world-class standing, while at the same time responding to local and national demands for increased access and greater accountability to society. Similarly they are seeking to maintain and develop important elements of their unique curricular heritage in a diverse higher education system, while at the same time becoming both more comprehensive in curricular coverage and more research-intensive.

\section{References}

Clark, B. (1998). Creating entrepreneurial universities: Organizational pathways of transformation. Oxford: Elsevier.

Hayhoe, R. (2006). Portraits of influential Chinese educators. Hong Kong: Comparative Education Research Centre, University of Hong Kong, and Springer.

Hayhoe, R., Li, J., Lin, J., \& Zha, Q. (in press). Portraits of 21 st Century Chinese Universities: In the Move to Mass Higher Education.

Li, J. (2009). Fostering citizenship in China's move to mass higher education: An analysis of students' political socialization and civic participation. The International Journal of Educational Development, 29(4), 382-398.

Li, J., \& Lin, J. (2008). China's move to mass higher education: An analysis of policy making from a rational framework. In D. P. Baker, \& A. W. Wiseman (Eds.), International 
perspectives on education and society: The worldwide transformation of higher education (pp. 269-295). Bingley, UK: JAI Press.

Zha, Q., \& Lin J. (in press). China's move to mass higher education: The policy process. Higher Education Policy. 